\title{
Deterrence and Specific Offenses
}

\author{
Johannes Andenaes†
}

Deterrence should not be treated as a monolithic problem. General propositions accepting or rejecting deterrence ought to belong to the past. The question is not whether punishment has deterrent effects, but rather under what conditions and to what extent the deterrent purpose is effected.

It is important initially to distinguish between the deterrent effect of the threat of punishment (general deterrence) and the deterrent effect of the imposition of punishment (special deterrence). ${ }^{1}$ Professor Chambliss has suggested that the distinction between general and special deterrence, perhaps useful in the abstract, is difficult to maintain in empirical research and may in fact obscure more than it clarifies. $^{2}$ His own discussion, however, demonstrates that failure to make the distinction may lead to mistaken conclusions. Chambliss concludes, on the basis of research showing high rates of recidivism among drug addicts, that drug addiction, like murder, is relatively unaffected by either the threat or imposition of punishment. ${ }^{3}$ This statement may be correct if restricted to those users who have already become addicts, since the great physiological need for drugs may vitiate the deterrent effect of punishment. But it is not correct to presuppose, as does Chambliss, that the limited success in the treatment of drug addicts necessarily suggests a similar failure to deter non-addicts and drug dealers. In fact, statistics concerning recidivism among drug addicts reveal nothing about the deterrent effect of drug laws on nonaddicts and drug dealers. Howard Becker's study of the marijuana user may be instructive. ${ }^{4}$ Becker identifies three stages in the career of a marijuana user: beginner, occasional user, and regular user. The be-

† Dean of the University of Oslo Law School and Director of the Institute of Criminol, ogy and Criminal Law, University of Oslo.

1 On the question of terminology see Andenaes, The General Preventive Effects of Punishment, 114 U. PA. L. Rev. 949 (1966), and Hawkins, Punishment and Deterrence: The Educative, Moralizing, and Habituative Effects, 1969 Wrs. L. REv. 550.

2 Chambliss, Types of Behavior and the Effectiveness of Legal Sanctions, 1967 Wis. L. REv. 703, 704 n.3.

3 Id. at 708.

4 H. BECKER, OUTSTEERS ch. 4 (1963). 
ginner is faced with two major obstacles created at least in part by the drug laws. First, he must overcome his fears of criminal penalties and social disapproval. Second, even if he overcomes these fears, he must locate a supplier. Since sale of the drug is subject to severe criminal penalties, its distribution is confined to illicit, not readily available sources. ${ }^{5}$ Thus, even though special deterrence with regard to the convicted drug addict may fail, general deterrence may operate effectively to prevent potential users from becoming addicts.

In discussing deterrence it is also necessary to distinguish among offenses. Common sense tells us that the threat of punishment does not play the same role in offenses as different as murder, rape, tax evasion, shoplifting and illegal parking. The different offenses vary greatly as to both motivation and extralegal restraints upon commission of the crime. Chambliss agrees that deterrent effects differ according to the type of offense, but makes a general distinction between expressive and instrumental acts. An act such as drug use or murder is expressive in that it "is committed because it is pleasurable in and of itself and not because it is a route to some other goal."6 Acts such as parking violations and shoplifting are, on the other hand, instrumental. According to Chambliss, the available research suggests that expressive acts are resistant to punishment as a deterrent, whereas instrumental acts are more likely to be influenced by the threat or imposition of punishment.

The analytical value of Chambliss' distinction is doubtful. It does not seem self-evident that expressive acts are less influenced by social sanctions than are instrumental acts. Experience from social intercourse shows that the fear of even mild social sanctions often leads to the suppression of expressive acts (for example, yawning, picking one's nose, or crying out angrily).

Moreover, the distinction does not seem very clear. For instance, Chambliss considers the use of narcotics a typically expressive act. It may seem pedantic to object that taking the drug is instrumental in bringing about the ultimate effects of the drug. But certainly the purchase or possession of the drug is instrumental in relation to the later use. Criminal acts to obtain the drug or to obtain money to buy it are even more clearly instrumental. Yet experience seems to show that the

5 Hauge gives a similar description from Oslo. The use of marijuana and hashish is relatively widespread in some circles in Oslo, but even if one could identify these circles, it would be a long time before they would trust him enough to sell the drugs to him. If the individual were conspicuously different from those in the drug-using circles, they would probably never sell drugs to him. Hauge, Narkotikamisbruk som Gruppefenomen (The Use of Narcotics as a Group Phenomenon), PRISMET 161, 163-64 (1969).

6 Chambliss, supra note 2, at 708, 712. 
desperate addict is deterred no more from committing these instrumental acts than he is from committing the expressive act-use of the drug. Thus, what leads to a lack of deterrent effect is not the expressive character of drug use, but rather the overwhelming motivating power of the addiction. That carefully planned acts are more easily deterred than those that result from a sudden, emotional impulse is an old proposition. The latter acts are probably more commonly labeled expressive. Apart from this distinction, however, referring to the act as expressive or instrumental does not seem to give a significant clue to the problem. A much more detailed analysis is needed.

I have previously discussed the general deterrent effect of punishment in relation to six broadly defined categories of offenses: violations of police regulations; violations of economic legislation; crimes against property; moral offenses; murder; and political crimes. ${ }^{7}$ In this article I shall consider three more specific offenses: infanticide, criminal abortion and drunken driving. The discussion is limited to general deterrence, using the term "deterrence" broadly to include the possible moral or habit forming effects of criminal laws.

\section{INFANTICIDE}

Infanticide, typically an unmarried woman's murder of her newborn child, was one of the great problems of the criminal law in the eighteenth century. Erik Anners, a Swedish legal historian, has provided useful information on the crime in his study of criminal law reforms during the Age of Enlightenment. ${ }^{8}$ Although rare until the end of the sixteenth century, infanticide became more common during the seventeenth and eighteenth centuries and came to be regarded as a major social evil. The increased frequency of infanticide seems to have been attributable primarily to the development of stronger religious and legal proscriptions of extra-marital relationships. These pressures created a strong temptation to hide the pregnancy and kill the child after its birth.

When the infanticide rate increased, due partly to the law itself, the threat of severe punishment was considered to be the only remedy. Therefore, partly for deterrent reasons and partly because of the religious view that a life must be paid for with a life, infanticide became a capital crime. Between 1759 and 1778, 217 of the 617 executions in Sweden were for infanticide. Those executed were usually from the poorer classes, and more often than not were countryside

7 Andenaes, General Prevention-Illusion or Reality? 43 J. Crim. L.C. \& P.S. 176, 181-90 (1952).

8 E. ANNERs, Humanitet och RATIONALISM (Humanitarianism and Rationalism) (1965). 
housemaids. The situation in other European countries was basically the same.

In the late eighteenth century, King Gustav III $^{9}$ of Sweden attempted to reduce the punishment for infanticide. He argued, perhaps to disarm his opponents, that capital punishment was an inadequate deterrent. He urged that a woman convicted of infanticide be first flogged and then imprisoned, perhaps for life. On the anniversary of the crime she was to be flogged before the common people. The King thought that this would create disgust for the crime and fear of the punishment. Opposition from conservative jurists and theologians, however, prevented enactment of these reforms. Not until 1861 was capital punishment for infanticide abolished, although granting of pardons had ended executions for the offense a generation earlier. ${ }^{10}$

It is difficult to ascertain the frequency of infanticide in eighteenth century Sweden. In 1773 the Swedish Supreme Court stated that infanticide and abortion are "yearly committed in such numbers over the whole country that the country loses considerably in population due both to the crime itself and to the ensuing penalty." Crime statistics and execution records, however, do not support so strong a statement. The Supreme Court must therefore have presumed that infanticide was committed much more frequently than the statistics indicated, and some evidence suggests that this assumption was correct. ${ }^{11} \mathrm{It}$ is also possible that the punishment itself, severe even to people of that era, contributed to the feeling that infanticide was a great problem.

Veli Verkko, a Finnish statistician, has investigated the frequency of infanticide in Finland and Sweden during the eighteenth century, when the two countries were united and ruled by the same law. ${ }^{12}$ His investigations, based on an evaluation of death statistics, reveal that the frequency of illegitimate births was greater in Sweden, but that the frequency of infanticide was greater in Finland. In Finland, the infanticide rate was highest in those counties in which the frequency of illegitimate births was lowest. His fairly plausible explanation is that strong sexual mores and social bias against the unwed mother resulted in fewer pregnancies among unmarried women, but also caused many of those who did have an illegitimate child to commit infanticide. He concludes that: "[w]e have here an example of the peculiar phenomenon under which a rigid morality can have a criminogenic-crime-producing effect." 13

9 King of Siveden, 1771-1792.

10 Ih. Olivecrona, OM Dödsstraffet (On Capital Punishment) 53-54 (1891).

11 See E. ANNERs, supra note 8, at 142, 207-08.

12 Verkko, Barnamorden och Sexualmoralen i Sverige-Finland pa 1700-Talet, Nordisk TIDSSKRIFT FOR STRAFFERET 35 (1946).

13 Id. at 45 . 
Infanticide was still prominent in the crime statistics of the nineteenth century. ${ }^{14}$ In the 1860's there were annually between ten and twenty convictions for infanticide in Norway; and in Sweden, with approximately double Norway's population, there were between thirty and forty. In the twentieth century, infanticide has gradually become less frequent and the penalty has consistently become less severe. In Norway, between 1957 and 1966, seven persons were found guilty of infanticide. In five of these cases prosecution was waived, and in the two that were brought to court the defendants received a suspended sentence of imprisonment for the minimum term of one year. ${ }^{15}$ In Sweden, during the same period, eight defendants were convicted, but the sentences are not specified in the statistics.

What explains this decline in the frequency of infanticide? It is unlikely that increased knowledge of contraceptives is a major cause of the decline. The number of children born out of wedlock has not, in a long term perspective, dramatically decreased. In Norway, in 1866, 4,310 children, or about eight per cent of the total live births, were illegitimate. A hundred years later the number was 3,285, about five per cent of all live births. Thus, increased knowledge of contraceptives appears largely to have been neutralized by relaxation of sexual mores during this century. Furthermore, there is reason to believe that knowledge of contraceptives has been slow in reaching the levels of society in which infanticide was most prevalent.

Two further hypotheses seem more plausible as explanations for the decline in the infanticide rate. First, the more liberal attitude of society towards extra-marital relationships coupled with better care of illegitimate children serve to mitigate the stigma which formerly attached to an unwed mother. Second, the solution to an unwanted pregnancy, previously provided by infanticide, is now abortion. Both of these factors probably have had an effect, although a detailed discussion of them is outside the scope of this article.

In view of the decline in the infanticide rate during the last century, can one conclude that the severe eighteenth century penalties for infanticide were useless brutality without deterrent effect? Anners seems to come to this conclusion, ${ }^{10}$ but he may be too bold. One can-

I4 The development can be illustrated partly by the crime statistics and partly by the death statistics. Between these two sources there are, at least in Norway, discrepancies which are difficult to explain. Unfortunately, because of several rearrangements of the statistics, I have not been able to present them in a coherent graph of the development.

15 Information on the sanctions is provided by the Prison Department of the Ministry of Justice.

16 E. ANNERs, supra note 8, at 154. 
not reject out of hand the possibility that more unhappy women might have resorted to infanticide had the penalty been less severe. But neither can such a hypothesis be proven. What one can safely conclude, however, is that a social problem, previously thought to require drastic criminal penalties, has been solved in other ways. It is also likely that most people today would find it easier to accept an increased infanticide rate than to impose the severe penalties once thought to be required by religion and deterrence. History reveals that strong beliefs in deterrence, particularly when combined with the moral or religious belief that sin should be punished, can produce results which later generations will consider unnecessarily brutal.

\section{ABortion}

The abortion situation in most western countries is characterized by strict laws, weak enforcement and a high rate of criminal abortions. The number of illegal abortions is astronomic compared to the number of prosecutions or convictions for the crime. It is often said that the criminal law in this area is ineffective in that it does not have an appreciable effect on the abortion rate. This notion is reflected in a recent paper by B.J. George:

Will even the most wildly liberal abortion statute make much difference in the incidence of abortion? I doubt it. The gross rate of abortions probably remains unaffected by efforts at legal regulation of the practice: the chief question is how many of the abortions actually performed will be done openly in hospitals or clinics. ${ }^{17}$

Sanford Kadish states that:

[As a] hard fact [the] abortion laws do not work to stop abortion, except for those too poor and ignorant to avail themselves of black-market alternatives, and ... the consequences of their retention is probably to sacrifice more lives of mothers than the total number of foetuses saved by the abortion laws. ${ }^{18}$

These statements illustrate how even excellent scholars can be guilty of sloppy thinking, probably due in this case to the widespread skepticism among criminologists with regard to the efficacy of the criminal law.

It is undoubtedly true that many women who desire to terminate a pregnancy but who cannot do so legally successfully procure an illegal

17 B. George, The Law Governing Abortion, April 28, 1968, p. 12 (unpublished paper delivered at The University of Chicago Conference on Abortion). 
abortion. But it seems obvious that this is not true of all women who would have an abortion if available on request. Some women may be too helpless, too passive, or too poor to find and use the alternatives open to the more active and resourceful. In other cases, a woman who would have an abortion if available on request may hesitate to make the rounds from one doctor to another begging for help or to permit a "quack" to perform the abortion.

These conclusions seem obvious and are supported by statistical evidence. Follow-up studies of women whose requests for abortion were denied show that although a great number of them subsequently obtain a criminal abortion, this is by no means true for all. A Danish study revealed that eighty-one per cent of the 3,700 women whose requests for abortion were denied or withdrawn in 1958 and 1959 completed their pregnancies. ${ }^{10}$ The percentage among housewives was considerably higher than among office workers: eighty-eight per cent and seventy per cent respectively. Swedish inquiries showed similar results. ${ }^{20} \mathrm{~A}$ Norwegian study made before the abortion law was liberalized showed that only thirty-six per cent of the women whose applications for abortion were denied completed pregnancy. ${ }^{21}$ Married women were more likely to bear the child than unmarried women: thirty-nine per cent and twenty-eight per cent respectively. A study under the present law showed that sixty-eight per cent of the women whose applications were denied completed pregnancy: eighty-one per cent of the married applicants and fifty-four per cent of the single applicants. ${ }^{22}$ It thus seems clear that the percentage of women who complete unwanted pregnancies depends on such factors as marital and occupational status and on the more or less easy availability of criminal abortions. The stronger the motivation for abortion and the easier the access to criminal abortion, the higher the percentage of women who will solve their problem in this way.

Another possible method of assessing the effect of abortion legislation is to compare the change in legal abortions following a liberalization of the law with the trend in the birth rate. In places, such as the Scandinavian countries, where more liberal laws changed the accepted grounds for abortion only moderately, the number of legal abortions is

18 Kadish, The Crisis of Overcriminalization, 874 ANNaLs 157, 163 (1967).

18 Beretning om Mödrehjælpsinstitutionernes Virksomhed 45 (1963).

20 Ekblad, Induced Abortion on Psychiatric Grounds, Acts Psychlatrica et NeuroLogica SCANDinavica, supp. 99, ch. VIII (1955).

21 InNstilling fra StraffelovraAdet om Adgangen til a Avbryte Svangerskap (Report from the Penal Code Commission on Abortion) (1956).

22 Strom, Svangerskapsavbrot i Visse Höve, TIDSSKrIFt FOR DEN NORske LAE GEForening 761,769 (1969). 
too small to have a noticeable effect on the birth rate. ${ }^{23}$ In contrast, the number of legal abortions has increased dramatically in those Eastern European countries where post-war legislation legalized abortion at the mother's request. ${ }^{24}$ Concurrent with the increase in legal abortions was a sharp decline in the birth rate. In Hungary, the number of legal abortions in 1964 exceeded the number of live births by almost forty per cent. ${ }^{25}$ On the other hand, in East Germany and Albania, the two Eastern European countries that had not legalized abortion, there was a modest increase in the birth rate.

While the relationship between the birth rate and liberalized abortion law is not simple, an open-minded study of the statistics seems to support Professor Tietze, who, after a thorough study of the available information, concluded that the legalization of abortion has had a depressant effect on the birth rate in most Eastern European countries. ${ }^{26}$ The most striking example is Romania where abortion on demand was legalized in 1957 but again prohibited in 1966. The birth rate had declined from 24.2 per thousand in 1956 to 14.3 per thousand in 1966. It is estimated that the number of abortions in 1966 was four times the number of live births. The reasons for the repeal of the 1957 law were stated in the preamble to the 1966 law: "[there has been] great prejudice to the birth rate and the rate of natural increase." 27 The effects of the new law were dramatic. The birth rate jumped from 14.3 per thousand in 1966 to 27.3 per thousand in 1967, 26.7 per thousand in 1968 and 23 per thousand in 1969. ${ }^{28}$ It should be noted that in conjunction with the reversed abortion policy, the government increased family allowances and ceased official importation of contraceptives. In Bulgaria, a tightening of abortion legislation in December, 1967 , led to an increase (albeit not as great as in Romania) in the birth rates in 1968 and 1969. One can confidently conclude that the increased number of legal abortions in some of the East European countries includes some cases where previously a criminal abortion would

23 In the Scandinavian countries the total number of legal abortions is $5-10 \%$ of the number of live births.

24 The Soviet Union does not publish statistics on abortions and is not included in the discussion of Eastern European countries.

25 Tietze, Abortion in Europe, 57 AM. J. Pub. Health 1923, 1930 (1967).

26 Tietze, The Demographic Significance of Legal Abortion in Eastern Europe, 1 DEMograpHy 124 (1964). Professor Tietze also comments that in Hungary in 1952 and 1953 , before the liberalized abortion legislation, concerted efforts were made to enforce the existing abortion laws. "These efforts led to an increase in births in 1953 and 1954." Id.

27 Tietze, supra note 25, at 1931.

$28 \mathrm{H}$. David, Family Planning and Abortion in the Socialist Countries of Central and Eastern Europe, 1970, at 21, 127 (mimeo.). In Table 14 the changes in the birth rate after the 1966 law was passed can be followed from month to month. Id. at 131. 
have been performed and others in which the woman would have completed her pregnancy..$^{29}$

Paradoxical as it may seem in view of the high rate of illegal abortions, there are probably few areas where so little enforcement has so much effect as in the field of abortion. This is due primarily not to the effect of the criminal law on the motivation of women who want to terminate pregnancy, but rather to the effect on the medical profession. Since safe abortion requires a doctor, preferably in a hospital, and since the medical profession on the whole is quite susceptible to the threat of law and the censure of society, the legal prohibition may prevent the mother from obtaining abortion without respect to her own attitude. Moreover, abortion is an area of the law in which the law may itself have a moral impact. If abortion were legalized, women would find it easier to overcome the feeling of guilt that now often accompanies the act. It is probably of no great significance whether the mother is herself subject to punishment. It is enough that abortion is criminal. Legalization of abortion may also result in carelessness in the use of contraceptives, producing more unwanted pregnancies and increased demand for abortions. The effect of abortion laws is obviously dependent on a variety of factors including religious beliefs, attitudes of the medical profession, knowledge and availability of contraceptive techniques, and social and economic conditions.

Abortion and infanticide are both the result of pregnancy which is viewed as a threat to the future life or happiness of the mother. But infanticide is, in contrast to abortion, a simple, primitive crime which does not require expert assistance. Moreover, the moral inhibitions against infanticide are much greater than those against abortion. For these reasons the effect of criminalization on the two types of conduct differs markedly.

To avoid misunderstanding, it should be pointed out that the deterrent effect of making abortion criminal is not a decisive argument against the liberalization of abortions. It can be argued that the mother ought to have the right to decide for herself whether to complete a pregnancy. Assuming that an unwanted child is a greater evil than a terminated pregnancy, it seems logical to conclude from the usual rise in the abortion rate after liberalization that there is a legitimate need for abortion which is not met under present law. But the indications of a deterrent effect are not without impact on the argument over liberalization: the policy problem would be different and easier to

29 In Japan the great increase in the number of legal abortions performed after passage of liberal post-War legislation has been accompanied by a marked decline in birth rates. Tietze, Some Facts about Legal Abortion, in Human Fertirtiy and Population Problems 223, 228-29 (R. Greep ed. 1963). 
solve if there were no deterrent effect, that is, if it could be shown that the effect of liberalization would be only to legalize abortions which would be performed anyway.

\section{Drunken Drtving}

For many years the Scandinavian states have had strict legislation against drunken driving, coupled with strict enforcement policies. In Norway, for example, the law prohibits driving when the blood alcohol level exceeds .05 per cent. Any person suspected of drunken driving must submit to a blood test. Upon conviction, the driver's license is automatically revoked for one year and, in addition, the consistent policy of the courts has been to impose a prison sentence. This strict policy seems to have had a considerable effect on driver attitudes with regard to driving under the influence of alcohol, and drunken driving now causes a very small percentage of highway accidents. ${ }^{30}$ However, this legislation has been in force since a time when there were far fewer automobiles and accidents than today. It is therefore impossible to demonstrate statistically the impact of the legislation.

The situation is different in Great Britain, which recently adopted a new highway safety act. ${ }^{31}$ The new legislation retained existing provisions which led to conviction only in cases involving a high degree of intoxication but added a new offense: driving with an undue proportion of alcohol in the blood. The prescribed limit is eighty milligrams of alcohol in one hundred milliliters of blood (.08 per cent). If the police have reasonable cause to believe that a driver has been drinking or has committed a moving traffic offense, they may ask the driver to take a breath test. The police may always request a breath test if the driver has been involved in an accident. ${ }^{32}$ If the test indicates that the driver's blood alcohol content is probably above the legal limit, he may be arrested and taken to the police station. There the driver is requested either to submit to a blood test or, if he refuses, to furnish two urine specimens for analysis. Failure to cooperate with these requests renders the driver liable to the same penalties that attach to driving with the proscribed blood alcohol content. Upon conviction

30 See Andenaes, supra note 1, at 968-69.

31 Road Safety Act 1967, c. 30 (effective Oct. 9, 1967).

32 The proposal in Ministry of Transport, Rond Safety Legislation, 1965-66, CMnd. No. 2859, at 11 (1965), to give the police the power to make random tests did not receive the approval of Parliament. "The system of random checks, however unpalatable, is evidently the only way in which the new law can be enforced for it is usually only at levels in excess of $150 \mathrm{mg} . / 100 \mathrm{ml}$. that a motorist's conduct exhibits obvious signs of unfitness." 1966 CrIm. L. Rev. (Eng.) 65, 67. In the light of later experience, this seems to be too pessimistic a view. 
for the new offense, the driver's license is automatically revoked for one year, except in extraordinary circumstances, and the driver is also subject to a fine of up to $£ 100$, four months imprisonment, or both.

An intensive publicity campaign, beginning two weeks prior to the effective date of the Act (October 9, 1967) and continuing for four months, accompanied passage of the new law. The campaign, estimated to have cost nearly $£ 350,000$, was particularly intense in the beginning and during the December holiday season. News coverage and comments in the press, radio and television provided additional publicity for the new law. As a result, there was great public awareness of the new law, and unusual interest in highway safety in general.

Highway accident statistics were carefully compiled to gauge the effect of the new legislation. This is one of the few instances in which an effort has been made to learn the precise effects of a new policy. According to official figures, highway accidents decreased substantially after the Act took effect. ${ }^{33}$ The following table is compiled from those figures.

Percentage Decrease in Highway Casualties in Great Britain, October to December, 1967, CoMpared With

SAME PERIOD IN 1966

\begin{tabular}{lccccc}
\hline & Oct.* & Nov. & Dec. & Oct.-Dec. & Christmas \\
\hline Eatalities & 17 & 20 & 33 & 23 & 36 \\
Seriously injured & 15 & 15 & 22 & 17 & 30 \\
Slightly injured & 11 & 13 & 20 & 15 & \\
\hline
\end{tabular}

- Figures for October represent the period after the Act took effect.

In the first nine months of 1967 there was no consistent trend in the incidence of highway accidents; there was an increase over the previous year during some months and a decrease in others. Overall, there was a two per cent decrease in casualties as compared with 1966. Total traffic was estimated to have increased from 1966 by five per cent in October, two per cent in November, and to have decreased one per cent in December. Neither the figures for 1966 nor those for the first nine months of 1967 reflect any remarkable change in comparison with previous years. In the 1950's and 1960's there had been a slow but steady upward trend in highway casualties. The annual number of fatalities had increased from about 5,000 in the early 1950's to approximately 8,000 during the period from 1964 to 1966 .

After the passage of the Highway Safety Act of 1967, there was a larger decrease in serious accidents than in minor accidents. This result is in harmony with the findings of previous highway accident re-

33 Ministry of Transport Press Notices, No. 892 (Dec. 19, 1967), No. 78 (Feb. 8, 1968), and No. 157 (Mar. 21, 1968). 
search showing that accidents involving drivers with blood alcohol levels over .08 per cent tend to be more serious than the average accident. ${ }^{34}$ Different drinking and driving habits during the holidays may explain the great reduction during the Christmas season. While changes in weather conditions may influence the figures for each month, the consistency of the figures is remarkable.

A striking pattern emerges if the accidents are correlated to the periods of the day in which they occurred. During working hours ( 8 a.m. to 6 p.m.) the decrease is slight: two per cent of fatal and serious accidents in October and November; seven per cent in December. Between 8 p.m. and 4 a.m. the figures were thirty-six per cent in October, thirty-eight per cent in November and forty-one per cent in December. For the early morning hours considered alone they were even higher. The inevitable conclusion is that, in this socially important area, new legislation has had a considerable impact on people's behavior, at least temporarily. ${ }^{35}$

A study of about half of the fatal accidents in Great Britain in December, 1964, and January, 1965, showed that thirty per cent of the fatally injured drivers had more than .05 per cent blood alcohol content. Twenty-three per cent of the fatally injured drivers had more than .08 per cent blood alcohol content and twelve per cent had more than .15 per cent. Seventy-five per cent of the drivers killed between 10 p.m. and 2 a.m. had at least .05 per cent blood alcohol content compared with ten per cent of the drivers killed between $6 \mathrm{a} . \mathrm{m}$. and noon. ${ }^{36}$

34 See, e.g., R. Borkenstein, R. Crowther, R. Shamaate, W. Zief \& R. Zylman, The Role of the Drinking Driver in Traffic Accidents 176-77 (1964) [hereinafter cited as BORKENSTEIN].

35 A paper issued by the ministries involved before the law came into effect said that it had been calculated that in the absence of driving after drinking, the number of drivers involved in accidents would be reduced 6\%. Drinking and Driving-Background Information (issued on behalf of Ministry of Transport, Home Office, Scottish Development Department, Welch Office). That figure, which was considerably exceeded since the Act took effect, was apparently based on a computation by the Road Research Laboratory from the findings of the Michigan "Grand Rapids Survey." BorkensteIN, supra note 34. The survey was based on comparisons between drivers involved in accidents and a random sample of drivers. The report from the Ministry of Transport, supra, summarizes research findings of the Road Research Laboratory concerning the frequency of drinking among people involved in highway accidents. The Laboratory's report gives $12.6 \%$ as the reduction in total accidents which would have occurred if drivers with blood alcohol content of $.08 \%$ or more had been prevented from driving. Id. at 167-69. The method of computation of the Road Research Laboratory is explained in Alsop, Drinking Drivers, 170 NEW Soc'Y 12 (1965), and in Alsop, Alcohol and Road Accidents, Road Research Laboratory Report No. 6 (1966).

38 Older \& Sims, Blood Alcohol Levels in Road Accident Fatalities Occurring in Great Britain During December 1964 and January 1965, Road Research Laboratory Report No. 32 (1966). In the United States, blood tests performed on fatally injured drivers have revealed extremely high proportions of drunken drivers. A study of single vehicle accidents 
These figures do not mean, of course, that drinking was the cause of the accident in all cases, but the implications are obvious.

Several alternative hypotheses which might be thought to explain the decrease in highway accidents in Great Britain deserve discussion. It may be argued that increased awareness of the dangers of drunken driving rather than the threat of punishment led to the reduction in the number of accidents. This theory credits the publicity campaign rather than the law itself for causing the decrease. This argument, however, does not appear to be supported by the facts. There had been long-standing public discussion of the problem of drunken driving, and the publicity campaign began two weeks before the new law took effect. Yet, in the first eight days of October, 1967, there was a reduction in highway casualties (compared with the same period in 1966) of only two per cent-the same reduction obtained in the first nine months of 1967. In that portion of October after the Act took effect, the reduction was twelve per cent. The decrease in fatalities was one per cent in the eight days of October before the Act took effect and seventeen per cent for the remainder of the month. Moreover, surveys conducted among drivers in September, 1967, and January, 1968, showed that drivers' toleration of drinking and driving and their opinion of the amount they could drink without affecting their driving remained substantially unchanged..$^{37}$ It seems clear that the dramatic reduction in highway accidents is directly attributable to the new legislation. The report of the surveys concluded that the publicity campaign had been valuable only in the sense that it made drivers aware of the new law.

Even if this conclusion is accepted, it does not necessarily follow that the explanation for the decrease in highway accidents is the effect of the new law on alcohol consumption before driving. An alternative hypothesis is that drivers, expecting increased police surveillance during the period immediately following the effective date of the new Act, exercised greater caution in driving quite apart from the Act's effect on alcohol consumption. It may well be that some part of the reduction of accidents is due to this factor. However, the distribution of the decrease in accidents according to time of day indicates that the most important factor was change in drinking and driving habits.

in Westchester County, New York, showed that $49 \%$ of the drivers had blood alcohol content of $.15 \%$ or more, and that an additional $20 \%$ had blood alcohol content between $.05 \%$ and $1.5 \%$. Haddon \& Bradess, Alcohol in the Single Vehicle Fatal Accident, Experience of Westchester County, New York, in ACCIDENT RESEARCH 208, 211 (1964). See also McCarroll \& Haddon, A Controlled Study of Fatal Automobile Accidents in New York City, in Accident ReSEARCH 172 (1964).

87 Sheppard, The 1967 Drink and Driving Campaign: A Survey Among Drivers, Road Research Laboratory Report LR 230 (1968). 
An important question is whether the effects of the new law are permanent. Other cases exist where an initial reduction in the commission of the proscribed offense, resulting from a new law accompanied by intensive publicity, has been followed by an eventual return to the previous level..$^{38}$ There is some indication of a similar development in Great Britain. In the last three months of the first year in which the Act was in effect, fatalities were nine per cent less than in the previous year, seriously injured seven per cent and slightly injured seven per cent. ${ }^{39}$ While these decreases are less impressive than those for the months immediately following the effective date of the Act, the development is somewhat ambiguous. As stated above, December is probably the month in which the most social drinking occurs. In December, 1967, the decrease from the 1966 level was thirty-three per cent and in December, 1968, the decrease was thirty-two per cent. The figures for seriously injured were twenty-two and nineteen per cent and for slightly injured, twenty and eighteen per cent. Thus, the reduction in the level of casualties for this month was practically the same as in the first year of the law's operation. It is possible that other safety measures introduced by the Ministry of Transport during the year influenced these figures. Nevertheless, the Ministry's conclusion "that a fair proportion of the reductions are being maintained, although it is clearly too early to assess the long term effects," 40 seems well founded. Post mortem examinations of fatally injured drivers revealed that the percentage of such drivers with blood alcohol content of over .08 per cent fell from a previous average of twenty-eight per cent to fifteen per cent in the first year after the effective date of the Act. ${ }^{41}$

For the first twelve months after the effective date of the Act the total reduction in casualties compared to the previous year was ten per cent. This represents 1,152 fewer fatalities, 11,177 fewer seriously injured and 28,130 fewer slightly injured. Opinion polls indicate that a majority of the population favors the new Act. But when fifteen per cent of drivers who are fatally injured in highway accidents have blood alcohol content of over .08 per cent and eleven per cent have over .15 per cent, a serious drunken driving problem still exists. It

38 See, e.g., Middendorff, Desirable Developments in the Administration of Justice, II Collected Studies in Criminologigat Research 45, 59 (1966). Judge Middendorff discusses the German Second Road Traffic Act which became effective January 2, 1965.

39 The figures are taken from a communication to the Norwegian Committee on Traffic Research from the Road Research Laboratory, Ministry of Transport, and are for the months of July, August, and September, 1968.

40 Ministry of Transport, The Road Safety Act 1967 and its Effect on Road Accidents in the United Kingdom (undated mimeo.).

41 Road Research Laboratory Report No. 32, supra note 36, at 3-4 \& Table IV (referring to a Road Research Laboratory Report by R.F. Newbay in course of preparation). 
would be interesting to have comparable information from the Scandinavian countries, where drunken driving legislation is older and stricter.

A decrease in the deterrent effectiveness of the new law with the passage of time can be interpreted in three ways:

(1) The publicity in connection with the Act created an exaggerated fear of detection for drunken driving. Later, drivers began to make a more realistic assessment of the risk of detection, and consequently the deterrent effect was weakened. The law had been "oversold." In addition, many loopholes in the law gradually became public knowledge, thus reducing the deterrent effect.

(2) The motivating force of a risk is dependent not only on the intellectual knowledge of the risk, but also on the degree of awareness. If, for example, one witnesses a traffic accident, his awareness of the risks of driving is greatly increased. In the same way, it can be assumed that the risk created by a new law is fresh in the minds of drivers, especially if enactment is accompanied by intense publicity. This high degree of risk awareness is gradually weakened, even when no reassessment of the risk is made. It is impossible to maintain the same level of publicity after the initial period of the Act's operation, and even if this were attempted, public sensitivity would probably be reduced when the publicity lost its news interest. Thus, a certain decrease in the "shock effect" of new legislation must be expected as a normal development.

(3) To the extent that the immediate reduction of highway casualties is due not to a changed pattern of alcohol consumption, but to the general driver expectation of more intense traffic control, the effect of the new law will necessarily be temporary.

These considerations could have been evaluated more effectively had surveys of drivers been made periodically. This would have been an important supplement to the accident statistics and would have revealed more about the psychological effects which led to the decreases. The survey research that has been done failed to cover such questions as how drivers assess the risk of detection.

The foregoing discussion has been concerned primarily with the awareness of the risk of punishment. However, I do not intend to imply that the effects of the new legislation are a result only of fear. Although survey research does not indicate a change in attitudes toward drinking and driving per se, ${ }^{42}$ the desire to obey the law may well have played a considerable role in the change in behavior. Therefore, it cannot be

42 Road Research Laboratory Report LR 230, supra note 37 . This sort of change may come at a later stage, when the initial success of the law in reducing the accident rate has become known among drivers. 
assumed that similar legislation, even when enforced in the same manner as in Great Britain, will have the same effects in a country whose citizens view obedience to the law differently. My personal view, however, is that the major factor in the success of the British legislation is mere deterrence. Creation of similar awareness of risk in a different society would have similar results if the drinking patterns and the social characteristics of the drivers were approximately the same.

Statistical evidence of the general preventive effects of punishment is scarce. What broader conclusions can be drawn from the British experience? Why do the British statistics yield the unequivocal results which are usually so difficult to obtain? Two points should be mentioned.

First, driving under the influence of alcohol differs from traditional crimes in that conduct not previously criminal has been made criminal, and it is therefore possible to measure the total impact of the new law. Crimes such as murder, robbery, rape and burglary remain substantially the same from one generation to the next. Changes relevant to the deterrent effect of the law usually concern the level of penalties or the level of enforcement. With such crimes, instead of measuring the total impact of the criminal provisions, there is the more difficult task of measuring the marginal effect of a change in the penalty or the degree of enforcement.

Second, in this case statistics of highway accidents provide an independent measure of the effects of the law. It is thus possible to avoid many of the difficulties of measuring the extent of violations. When the scope of a penal law is extended or contracted, it is theoretically possible to measure the total impact of the extension or contraction of the law. But "before" and "after" tests in these situations are especially difficult because criminal statistics do not provide a "before" measure for conduct that is now criminal or an "after" measure for conduct that has ceased to be a crime.

It should be noted that the number of highway accidents resulting from drinking may not be presumed to vary directly with the number of violations of the drunken driving laws. The effect of the law often may be that the driver reduces his consumption in order to decrease the risk of detection, even though his blood alcohol content remains higher than the maximum legal limit. Because the risk of an accident increases as the amount of alcohol increases, such reductions in consumption may be very important in relation to the goals of the law. If the legal limit is low, a high proportion of fringe violators may be of minor importance for highway safety. Since the aim of the law is to promote highway safety, the influence of the law on the number of accidents is a better measure of its efficacy than would be "before" and 
"after" statistics on the number of drivers whose blood alcohol content exceeds the limit.

Since the change in accident statistics shows the total impact of the new legislation, it is a poor basis for forecasting the effects of changes in the level of penalties or in the stringency of enforcement. Norwegians generally accept the proposition that non-suspension of prison sentences imposed for drunken driving has been very important in promoting the deterrent effect of the law. In Great Britain, the sentence usually consists of a fine and temporary loss of the driver's license. This contrast gives reason for questioning the importance of prison sentences. Perhaps fines and license revocation can achieve almost the same results as prison sentences; but further discussion on this point would require a much more thorough study.

For several reasons, a stronger deterrent effect may be expected from drunken driving laws than from laws against many other types of offenses. Driving under the influence of alcohol is not restricted to a criminal sub-culture, and it is not subject to severe moral condemnation. Nor is it behavior triggered by strong emotions. The decision whether or not to drink is usually made deliberately, as a rational choice; and the motivation to commit the offense is not strong. The law interferes only slightly with personal liberty. It asks the citizen neither to stop drinking nor to stop driving. It merely prohibits combining the two activities. Thus, the drunken driving situation is one in which common sense tells us that the risk of punishment can be expected to have more effect than in the case of many other offenses. This point should not, however, be overstated. There is no standard of the normal or average crime to which drunken driving is an exception. Every offense must be considered separately. Indeed, the motivational situation in many socially important types of offenses may be more similar to drunken driving than, for example, to murder or rape.

As enforcement of a law becomes more effective and penalties for its violation become stricter, the class of lawbreakers becomes more abnormal. It is no doubt correct that drunken driving was common throughout the population before the passage of strict criminal sanctions. Distribution of the violators is not so widespread after the passage of the new legislation. The composition of the class of drunken drivers will be altered. Instead of a fairly random sample of drivers, the drunken drivers will be primarily the problem drinkers and those with previous records for drunken driving-people less amenable to being deterred. This fact must be taken into account in forecasting the effect of any increase in the level of enforcement or punishment of an offense which is already strictly enforced and punished. He who invests in increased severity, has to expect diminishing returns. 